\title{
De la anomalía a lo extraordinario: nobleza, linaje y escritura genea- lógica en Castilla (siglos XIII-XIV)*
}

\author{
Arsenio Dacosta \\ Universidad de Salamanca
}

RESUMEN: A partir del problema del retraso de la literatura genealógica castellana respecto de otros ámbitos europeos, en este trabajo se discute la pertinencia del uso de ciertas categorías historiográficas, muy en particular la de «linaje», para explicar una de las formas de sociabilidad básica de la nobleza bajomedieval. El artículo se hace eco de las principales discusiones teóricas en este terreno, relacionándose también con la cuestión de la oralidad y la escritura. Finalmente, se proponen algunas líneas de investigación como el análisis del concepto de linaje en las fuentes castellanas y peninsulares, en qué manera dicho concepto trató de ser capitalizado política y socialmente por Alfonso X, o cómo se concibe el linaje en los textos producidos por la nobleza castellana y su entorno en los siglos finales de la Edad Media.

PALABRAS CLAVE: linaje; genealogía; nobleza; literatura; escritura; oralidad.

From Anomaly to Extraordinary: Nobility, Lineage and Genealogical Writing in Castile (XIII-XIV Centuries)

ABSTRACT: Starting from the problem of the late start of Castilian genealogical literature compared to other European contexts, this article discusses the relevance of the use of certain historiographic categories, with a strong

* Este trabajo forma parte de los resultados del Proyecto de investigación De la Lucha de Bandos a la hidalguía universal: transformaciones sociales, politicas e ideológicas en el País Vasco (siglos XIV y XV), Ministerio de Ciencia e Innovación HAR2010-15960, del Grupo Consolidado de Investigación del Gobierno Vasco Sociedad, poder y cultura en el País Vasco (siglos XIV y XV), IT-600-13, y de la Unidad de Formación e Investigación de la Universidad del País Vasco 11/02. 
emphasis on that of "lineage», to account for one of the basic forms of sociability in the nobility of the late Middle Ages. The article echoes the main theoretical discussions in the field, relating them to the issues of orality and the written word. Finally, certain lines of research are proposed, such as the analysis of the concept of lineage in Castilian and other Peninsular sources; how Alfonso X of Castile attempted to capitalize on it politically and socially; or how lineage is conceived of in the texts produced by the Castilian nobility and its milieu in the late Middle Ages.

KEY WORDS: lineage; genealogy; nobility; literature; writing; orality.

Más recuerdos tengo yo solo que los que habrán tenido todos los hombres desde que el mundo es mundo.

Jorge Luis Borges, Funes el memorioso, 1944.

\section{El RETRASO de LA Literatura Genealógica CASTELLANA Y EL PROBLE- MA DEL CONTEXTO}

Es conocido que la genealogía, como género escritural, tiene una aparición tardía entre la nobleza castellana. En un trabajo reciente Jaume Aurell alude a ello en términos de «anomalía» planteando una sana duda al respecto ${ }^{1}$ en la que, al menos provisionalmente, merece la pena ahondar. Se asume que «la eclosión de la literatura genealógica $»^{2}$ en Castilla es muy posterior a su decadencia en Francia, donde había tenido un amplio desarrollo entre los siglos XI y XII ${ }^{3}$.

Fundamentalmente son tres los argumentos recurrentes al respecto. En primer lugar, la determinante influencia del contexto, en el que parece pesar de forma crucial la fortaleza o debilidad del poder regio. Segundo, la tardía consolidación del carácter agnático del parentesco nobiliario en la Corona de Castilla, conformando una estructura de crucial trascendencia histórica como es el «linaje». En tercero, se arguye la particular relación de la nobleza leonesa y castellana con la oralidad y la escritura. Aquí se analizarán, aunque sea sintéticamente, estos argumentos.

Para el caso francés, Carlos Heusch ha sostenido recientemente que la desaparición del género se produce en la baja Edad Media «a medida que se va

1 AURELL, 2013: 330.

2 BECEIRO PITA, 2013: 181.

3 Aluden a ello los estudios clásicos de BLOCH, 1986: 111; DUBY, 1973: 287-298. Un resumen más reciente en BECEIRO PITA, 50 (1995): 57-58. 
consolidando el poder regio, concretamente con soberanos como Carlos VII y Luis XI» ${ }^{4}$. Resulta difícil extrapolar esta conclusión a Portugal o Castilla, por cuanto este particular modo de escritura histórica aparece en contextos definidos por ambiciosos proyectos de fortalecimiento monárquico. El ejemplo portugués es muy expresivo: las principales redacciones de los llamados $\mathrm{Li}$ vros de linhagens — salvo el Livro Velho - se realizan bajo Afonso IV o Bra$v o^{5}$ y contienen, como señaló Mattoso, una fuerte carga reivindicativa para la nobleza lusa ${ }^{6}$. Para el caso castellano el problema es más complejo dada la inexistencia de nobiliarios generales o particulares antes de 1371, por mucho que se sospeche la existencia de algunos precedentes en el seno de familias de la alta nobleza como los Haro, los Castro o los Lara, entre otros ${ }^{7}$. Por otro lado, la verdadera expansión de este tipo de literatura en Castilla no llegará hasta finales del siglo XV coincidiendo con el reinado de los Reyes Católicos, constructores efectivos del estado moderno ${ }^{8}$.

4 HEUSCH, 2011: 2. Esta afirmación implica una profunda revisión de la cronología sostenida hasta la fecha para el caso francés. En un trabajo ya clásico, José Enrique RUIZ DOMENEC interpreta las genealogías nobiliarias francesas en términos de «representación» y sitúa la decadencia del género genealógico en el siglo XIII en estos términos: «no fue en el terreno de estas narraciones donde la re-presentación de la memoria alcanzó su plenitud creativo, sino en ese campo, nuevo, pero de diversión, de la novela en prosa» (1984: 239). En relación a estos textos es importante advertir que las genealogías condales francesas de los siglos XI y XII distan de ser exhaustivas y, lo que es más interesantes, no dejan de omitir personas o líneas del linaje que, según Charles de LA RONCIÈRE, «sont escamotés» (1982: 277).

5 Para el reinado de Afonso IV remito a la reciente biografía elaborada por VASCONCELOS (2009).

6 Para esta cuestión remito a MATTOSO, 44-45 (1983-1985): 73-92; y, del mismo, 2009b: 329. También lo señala KRUS, 1989, vol. II: 80 ss.

7 El Livro del Conde de Barcelos recoge informaciones genealógicas sobre estas casas y sobre otras como la de los condes de Trastámara. KRUS, 8 (1992): 43-49. Ya son numerosos los estudios que abordan directamente la cuestión en relación a estas grandes casas, particularmente los de PAREDES NÚÑEZ (1995). Para los Lara remito a tres estudios, uno antiguo y dos recientes: CIROT, 28 (1926) y 29 (1927); ESCALONA, 23 (2000): 113-176; MARTIN, 2012. En el caso de la leyenda genealógica de los Haro transmitida por Pedro de Barcelos $-\mathrm{y}$ después por Lope García de Salazar-, hemos de recordar que el profesor MATTOSO - siguiendo a García de Cortázar - afirmó «que foram extraídos de uma obra da Biscaia, hoje perdida» (1983: 10). La cuestión nos excede, pero la aborda en detalle, con alusión expresa a posibles fuentes orales y a la tradición folklórica local de este motivo legendario, PRIETO LASA, 1995: 271 ss. Un panorama general sobre la literatura genealógica hispana en PARDO DE GUEVARA, 2012: 19-31. Tras la aceptación de este artículo se ha publicado una obra colectiva sobre la materia.

8 Véanse al respecto: CONTRERAS, 21 (1995): 105-124; NIETO SORIA, 29 (2006): 301-316; LADERO QUESADA, 198 (2001): 205-314; PARDO DE GUEVARA, 2012: 26 ss. También es de referencia el estudio y edición de CÁTEDRA (2003) de La Historia de la Casa de Zúñiga, otrora atribuida a mosén Diego de Valera. Para el caso francés remito a MAUREL, 46/4 (1991): 807-825. 
El contexto político es, con todo, uno de los factores que ayuda a comprender la génesis y difusión de la literatura genealógica ${ }^{9}$, pero posiblemente no sea el determinante en uno solo de sus vectores, léase la debilidad o fortaleza del poder regio ${ }^{10}$. Una variante de esta hipótesis ha sido formulada no hace mucho por Miguel Calleja, quien vincula el retraso de «narraciones genealógicas» en Castilla $-\mathrm{y}$ su aparición más temprana en Portugal - al hecho de que «la perduración de la experiencia fronteriza contribuyó a mantener una vía de escape en la dinámica interna de los grupos familiares, y a ralentizar su reequilibrio interno a favor de la primogenitura», esto es, al retraso de «la constitución de una nobleza de linaje» ${ }^{11}$. Esto permite entrar en el segundo de los argumentos señalados.

Las excepcionalidades que se encuentran en el primer texto genealógico castellano, el de Fernán Pérez de Ayala datado en $1371^{12}$, manifiestan, por sí mismas, su carácter precursor en el contexto castellano; sin embargo, esta explicación no es suficiente. Se puede asumir que la memoria genealógica va estrechamente ligada a la difusión del linaje como marco básico de sociabilidad de la nobleza pleno y bajomedieval. Ahora bien, establecer una relación causal entre uno y otro fenómeno no parece tan sencillo. A mi juicio, no es tan fácil argumentar un retraso en la implantación y evolución del linaje noble en los reinos de León y de Castilla respecto de otras latitudes a menos que se asuma que el linaje sólo puede definirse antropológicamente como agnático ${ }^{13}$, y que no es posible identificar una evolución en sus formas y manifestaciones.

9 Así lo demuestra Jaume AURELL 36 (2005): 235-264, cuando desvela la determinante influencia del contexto en la redacción de la Gesta Comitum Barcinonensium y del Llibre dels Fets.

10 Para el caso portugués PAREDES NÚÑEZ insiste en lo ya señalado sobre la reivindicación estamental de la nobleza contrastándolo con la «decadencia del género en la época en el resto de Europa» 8 (1991): 173. Estamos expresando nuestras dudas sobre tal argumento, es decir, creemos que las genealogías nobiliares cumplen esta función vindicativa — particular o estamental - en todos los contextos políticos, algo que abordo comparando el caso castellano y el portugués en DACOSTA, 8 (2010). Así se deduce también, algunos siglos antes, entre la aristocracia franca la cual, en sus textos genealógicos, reclama expresamente «a place in a shared past», en palabras de WOOD (2004: 234-236; citado por REIMITZ, 2012: 23).

11 CALLEJA, 16 (2010): 128. Esta hipótesis sobre la «sociedad de frontera» es también valorada por BECEIRO (2013: 79) en relación al retraso de la literatura genealógica castellana.

12 Aunque se le ha conocido como "Árbol de la Casa de Ayala», un título más apropiado para esta obra es el de «Libro del linaje de los señores de Ayala» (la edición más reciente es la de DACOSTA, 2007: 135-155).

13 En palabras de GOODY, «este lenguaje no está normalizado», pudiéndo hacerse distinciones de matiz entre los conceptos de agnatismo, patrilinealidad o simplemente «descendencia por línea paterna» (1986; 31, nota 2 y 303 ss). Véase, al respecto, la acerada crítica que NASSIET hace respecto del uso del concepto de "patrilinaje» entre los medievalistas (50 (1995): 621-644; citado por MORSEL, 2007: 116, nota 105). 
De hecho, una mirada retrospectiva a la historiografía española revela, en primer lugar, no pocas paradojas y contradicciones al respecto ${ }^{14}$. En el caso de las aportaciones más recientes es evidente la falta de consenso en el uso del término «linaje» en relación, al menos, a la nobleza alto y plenomedieval. De un lado, unos evitan expresamente este uso, apostando por términos aparentemente más neutros como «parentela» o por los que, parcamente, reflejan las fuentes ${ }^{15}$. Otros niegan la existencia del «linaje» antes de la baja Edad Media en razón de su caracterización como una estructura esencialmente agnática ${ }^{16}$. Finalmente, se encuentran los que utilizan abiertamente el concepto de «linaje» ${ }^{17}$, aunque puntual y casi subrepticiamente reconozcan los problemas que derivan de ello ${ }^{18}$.

Afortunadamente esta falta de consenso no parece afectar a la caracterización general de la nobleza antes del siglo XIII, aspecto en el que se ha avanzado enormemente en los últimos años. Es más, el consenso se extiende a la cronología del fenómeno linajístico - en su versión agnática - en el ámbito leonés y castellano, aunque con matices. Según se ha destacado, «Pascual Martínez Sopena detecta los comienzos de una organización linajística para la aristocracia leonesa desde el siglo XI», y otros autores como Isabel Beceiro y Ricardo Córdoba de la Llave «sitúan en el siglo XIII y en la primera mitad del XIV el triunfo del agnatismo, al tiempo que observan en el siglo XII el comienzo de los rasgos del linaje» ${ }^{19}$, aunque los mismos autores destaquen igualmente el peso de los elementos «bilaterales o cognaticios» de las estructuras de parentesco de la nobleza castellana ${ }^{20}$. Como se deduce de las eviden-

14 Sobre la «mirada galocéntrica» de la historiografía española en relación a las estructuras de parentesco de la nobleza castellano-leonesa, y las contradicciones y paradojas de su recepción en relación a la interpretación general del feudalismo hispánico, véase PEREZ, 42 (2010): 170-172. En este interesante trabajo se aborda una sintética e ilustrativa descripción de los problemas de recepción de algunas teorías antropológicas sobre el parentesco (principalmente el evolucionismo y el estructuralismo) entre los medievalistas españoles. La adaptación — más o menos hábil— del aparato conceptual y teórico de los antropólogos del parentesco entre los medievalistas ha sido criticada con dureza en distintos trabajos por MORSEL 125 (2004): 83-110, y 2007: 40, nota 28.

15 CALLEJA, 2001; CALDERÓN MEDINA, 2011.

16 Aunque no resuelve la cuestión, por lo menos se aborda expresamente en ÁLVAREZ BORJE, 2002: 76 ss. En un artículo más reciente, el mismo autor ha insistido en «que no existe todavía en este periodo una organización linajística de la nobleza», aunque matiza que «hay ciertos elementos que apuntan hacia ella entre los sectores de la alta nobleza» ÁLVAREZ BORJE, LXX/235 (2010): 385.

17 TORRES, 1999; SÁNCHEZ DE MORA, 2007.

18 Recientemente, Margarita Torres matiza el contenido del concepto cuando afirma que «Lentamente, durante el siglo XII, la tendencia se consolida, vertebrando un nuevo sistema que, sin duda, ya puede recibir el nombre de linaje» TORRES, 102 (2009): 115.

19 Los entrecomillados están tomados de PALLARÉS y PORTELA, 5 (1994): 55, nota 2.

20 BECEIRO y CÓRDOBA, 1990: 36. 
cias documentales y de los análisis aportados por Martínez Sopena, la respuesta no está en el agnatismo - esto es, en una categoría institucional- sino en el terreno de las prácticas sociales.

Se trata, en suma, de un problema de concepto que exige ser abordado, aunque presente dos retos de entidad. El primero, relativamente fácil de resolver, es lo que se puede deducir de las fuentes. El segundo, más complicado, exige que, tras revisar críticamente lo que ha aportado el medievalismo a la cuestión, se escuche atentamente a los antropólogos y que después, sólo si procede, se adapte su utillaje conceptual a nuestra disciplina ${ }^{21}$.

Para la primera cuestión contamos con los trabajos de Pascual Martínez Sopena quien, hace años, señaló la necesidad de analizar esta terminología 22 . No faltan en estudios posteriores una labor más o menos sistemática al respecto, pero, a mi juicio, no se ha hecho aún un trabajo de exégesis del término «linaje». Recientemente el profesor Miranda ha ofrecido un análisis comparado de las fuentes literarias ibéricas del siglo XIII con resultados prometedores $^{23}$. Hoy se está en condiciones de asumir esta tarea de forma cómoda con las herramientas y método que sugiere Ana Isabel Carrasco ${ }^{24}$. Se conocen bien las distintas acepciones del término «linaje» en las fuentes del siglo XIII; ahora falta precisar su significado en cada contexto documental con el fin de verificar la validez o no del concepto subyacente y, sobre todo, desterrar una suerte de difusionismo latente - particularmente en la historiografía francesa- que vincula la aparición del término en lengua romance con el nacimiento de unas estructuras supuestamente regidas por el agnatismo ${ }^{25}$.

Una búsqueda en algunos corpus disponibles como a los que recurre el profesor Miranda permite confirmar algunas cuestiones respecto del término. En primer lugar, el hecho de que la primera mención literaria conocida para Castilla, de la mano de Berceo, ya exprese claramente la identificación entre linaje y nobleza e, implícitamente, el papel político y moral —el bien común y el sacrificio- que ésta debía jugar en el reino:

Mandó a los christianos / el qe mal siglo prenda, / qe li diesen cadaño / tres vent' dueñas en renda, / las medias de lignage, / las medias chussorrenda; / ¡mal sieglo aya preste / qe prende tal ofrenda! ${ }^{26}$

21 Véase al respecto la advertencia de GUERREAU-JALABERT, 1990: 105.

22 MARTÍNEZ SOPENA, 5 (1987): 33-87.

23 MIRANDA, 11 (2011).

24 Explora las posibilidades y desafíos de este tipo de análisis CARRASCO, 34 (2011): 343-372.

25 Agradezco a la Dra. Ferrero Hernández, de la Universitat Autònoma de Barcelona, sus reflexiones en este sentido. Un breve pero revelador estado de la cuestión se ofrece en MARTÍNEZ SOPENA, 2 (2008).

26 Vida de San Millán de la Cogolla, III, 340. Cito por la edición de DUTTON, 1967. MIRANDA, por su parte, afirma que «A primeira obra literária em castelhano onde pela pri- 
En segundo lugar, el concepto, con análogo significado, puede rastrearse en la documentación notarial del ámbito castellano-leonés en el primer tercio del siglo XIII ${ }^{27}$, lo que expresa su correspondencia con la realidad social del momento. Tercero, la difusión del término se da en distintas formas y contextos de producción en el siglo XIII con especial frecuencia en su segunda mi$\operatorname{tad}^{28}$. Finalmente, el análisis de las primeras menciones de «linaje» en las lenguas romances peninsulares desvela que el término se estaba empleando para reflejar realidades de diversa naturaleza ${ }^{29}$. Posiblemente un trabajo sistemático no resuelva totalmente la cuestión del significado, pero sin duda ayudará a salir del actual estancamiento conceptual, utilizando precisamente aquello que mejor domina el historiador: los documentos ${ }^{30}$.

meira vez detectámos o uso de «linhagem» é a Vida de Santo Domingo de Silos (1230?1240?)» (11 (2011): 46).

27 MIRANDA, 11 (2011): notas 13 a 16. Una consulta al CODEA (Corpus de Documentos Españoles anteriores a 1700, de la Universidad de Alcalá), confirma la información aportada por Miranda: el más antiguo documento en el que hallamos el concepto de linaje en el sentido que nos ocupa es una donación de 1236 a la abadía de Sahagún (Archivo Histórico Nacional. Clero, León, 914, $\mathrm{n}^{\circ}$ 9), esto es, contemporáneo a las vitae de Berceo.

28 El estudio de referencia es, sin duda, el del profesor MIRANDA quien plantea la difusión del término linaje a partir del Liber Regum y de la literatura trovadoresca, todo ello al filo de 1200. La cronología de esta difusión, aun cuando se pueda aportar algún matiz, es estrictamente contemporánea a escala peninsular (11 (2011): $11 \mathrm{ss)}$. A diferencia del excelente trabajo del profesor Miranda, mi consulta al CORDE (Corpus diacrónico del español, de la Real Academia Española) ha sido meramente orientativa. La frecuencia del término «linaje» / «linage» ha arrojado casi 1700 ejemplos anteriores al año 1300, pero mi selección no distingue entre las variadas acepciones que tiene el término (véase ALONSO, 1986, II: 1313). No obstante, sí puedo confirmar que se encuentra con un claro significado social, esto es, aludiendo a la nobleza, en todo tipo de documentos: fuentes historiográficas y hagiográficas, textos jurídi$\cos$ y literatura sapiencial, documentación notarial, y en textos literarios como el Libro de Aleixandre o el Poema de Fernán González.

29 Es la hipótesis que maneja José Carlos Ribeiro Miranda para las menciones galaicoportuguesas y castellanas del siglo XIII. Según este autor, en esta época se asiste a la «consolidação de dois usos distintos de «linaje, linhagem», uno de valor diacrónico definido como «o pasado geracional de um indivíduo ou de um colectivo assumido como um todo», y otro como «a relação sincrónica entre parentes próximos». MIRANDA, 11 (2011): 49 ss.

30 En absoluto pretendo ser injusto con los colegas españoles y europeos, para los que no es ajeno el trabajo de conceptualización. Como muestra de ello y sin ánimo de ser sistemático, remito a algunos recientes: MATTOSO, 2009a, LARREA, 2002, LÍBANO y VILLACORTA, 11 (2008), MARTÍNEZ GARCÍA, LXX/235 (2010). Aún así, ha de admitirse la acerada crítica de GUERREAU, 2002: 181 ss., y más cuando se reclama recurrentemente la necesidad de realizar periódicamente este tipo de esfuerzos. 


\section{EL LINAJE: DE LA ILUSIÓN AGNÁTICA A LAS ESTRATEGIAS DE REPRODUC- CIÓN SOCIAL}

El aludido estancamiento conceptual me lleva a la segunda cuestión conflictiva, la caracterización del linaje como estructura de parentesco definida por el agnatismo. A su clarificación no sirven, aparentemente, las expresivas prescripciones contenidas en las Partidas, que bien apuntan al agnatismo como señal distintiva del linaje hidalgo ${ }^{31}$, o bien lo definen de una forma más extensa $^{32}$, y más cuando éstas se comparan con sentidos distintos del término linaje recogidos en el Fuero Real ${ }^{33}$. La obra legislativa de Alfonso X también ofrece problemas de interpretación respecto de términos clave como hidalguía y nobleza, pero una revisión atenta de ese corpus puede revelar que las indefiniciones y contradicciones no lo son en su contexto y significación política. Aunque la efectividad normativa de las Partidas no se extiende al conjunto de la sociedad castellana hasta después del Ordenamiento de Alcaláa ${ }^{34}$, la obra de Alfonso X estaba reflejando una realidad social madura. Utiliza ya la definición de linaje no de forma teórica - para difundirlo como forma de sociabilidad deseable para la elite social-, sino como mecanismo de control regio del acceso a la nobleza - como estamento jurídicamente sancionado- y a la caballería - como práctica exclusiva de dicho estamento ${ }^{35}$ - .

Ciertamente, el linaje aristocrático en los siglos XII y XIII parece presentar algunas características diferenciadas respecto de las centurias siguientes. Las más destacadas son la creciente importancia de los vínculos agnáticos - a pesar de que el sistema conservará hasta el triunfo pleno del mayorazgo e incluso después un marcado carácter bilateral-, la vinculación legal de los bienes del linaje en la persona del primogénito varón, y la evolución de los vínculos agregados al linaje en un sentido político, particularmente los derivados de las estrategias de alianza y de las redes clientelares ${ }^{36}$.

Es tentador asumir que, al calor del cambio dinástico en Castilla, en el último tercio del siglo XIV, se produce una evolución de las estructuras de

31 Partida Segunda, título XXI, ley 2.

32 Partida Cuarta, título VI, ley 2.

33 En un sentido «sincrónico», tal y como señala el profesor Miranda, aparece en el Título I, ley 2, libro III y en el título IV, ley 1, libro XVII (MIRANDA, 11 (2011): 43 ss).

${ }^{34}$ Lo recuerda HEUSCH, 11 (2011): 2.

35 Aborda la cuestión con su brillantez habitual MARTIN, 2004: 219-234. Insiste en esta perspectiva el profesor Miranda cuando afirma, «Paralelamente, «linhagem» pode constituir também —num proceso afimao que virá a suceder com «cavalaria»—o definidor genérico de todo o estamento nobre, traço de conteúdo que está, de uma maneira ou de outra, presente na esmagadora maioria destes usos que rastréamos» (MIRANDA, 11 (2011): 52).

36 En este sentido, son expresivos los paralelismos con el caso portugués, con una crítica directa al modelo propuesto por Duby, que encontramos en VASCONCELOS, LXVII/227 (2007): 889 ss. 
linaje ${ }^{37}$. Varios son los elementos que apuntan a ello: la renovación de cuadros en el seno de la nobleza, la aparición de mecanismos jurídicos de vinculación al primogénito — léase, el mayorazgo en sus distintas formas ${ }^{38}$ - y sobre todo la más influyente idea de que la nobleza debe servir al rey y al reino además de al propio linaje. Estos factores, junto con la «regulación de la hidalguía», en palabras de Miguel Calleja, «acentuaron la necesidad social de las reconstrucciones genealógicas $\rangle^{39}$.

A pesar de los denodados esfuerzos de algunos investigadores, la determinación conceptual del linaje para la alta Edad Media hispana no está muy lejos de donde quedó problematizada en un influyente libro coordinado por Reyna Pastor que vio la luz en $1990^{40}$. Jack Goody reclamaba no mucho antes la necesidad de abordar la cuestión terminológica ofreciendo una sugerente discusión a partir de las obras de Duby y Guichard ${ }^{41}$. En resumen, merece la pena evaluar si medievalistas y antropólogos nos hemos estado refíriendo a lo mismo cuando hablábamos del «linaje» ${ }^{42}$. De hecho, entre los segundos se está manteniendo un intenso debate epistemológico — al que el medievalismo francés no es totalmente ajeno- que tiene al «linaje» - y al «parentesco» en general- en su punto de mira ${ }^{43}$. También cabe superar una visión estructura-

37 Así lo valora en relación también a la literatura genealógica BECEIRO, 2013: 81.

38 De facto, hay autores que encuentran algunos ejemplos de mayorazgo en el siglo XIII, particularmente entre los Dávila y otros linajes abulenses. MORENO NÚÑEZ, 5 (1984): 695708. Parece superado el criterio de que el mayorazgo solo puede aceptarse si media la sanción regia. El mayorazgo - como el linaje - debe ser interpretado en términos de estrategia de poder, lo que explica que su extensión e institucionalización sean progresivas y tardías.

39 CALLEJA, 16 (2010): 134.

40 PASTOR, 1990. Tuvo una suerte de continuación en un monográfico de la revista Hispania donde de nuevo Reyna Pastor planteaba abiertamente: «Un primer problema que aparece al abordar estos temas y precisar los conceptos operativos, es el de las relaciones de parentesco (con todas sus variables), el de linaje, el de casa, etc. Linaje, por ejemplo, es un concepto que se aplica de manera diversa a organizaciones parentelares distintas, en la historiografía medieval al menos» PASTOR, LIII/3, nº 185 (1993): 792.

41 GOODY, 1986, apend. 1: 227 ss. Goody omitió en su análisis la obra de Karl Schmid cuyo uso del utillaje antropológico, junto a Georges Duby, es criticado en paralelo por MORSEL, 2007: 115-116. Contrariamente a la «mutation lignagère» que constituye el eje explicativo de Schmid y Duby, Morsel defiende que la formación de linajes obedece «à un phénomène de soumission des rapports de parenté à l'imperatif de réproduction d'un pouvoir enraciné» (2007: 150).

42 A pesar de la claridad expositiva de Martine Segalen — posiblemente la mayor experta francesa en la materia actualmente- las categorías antropológicas de filiación, y muy especialmente las de la filiación unilineal, no están exentas de «contradicciones con los principios de funcionamiento del grupo» y no funcionan «según el mismo modelo en todas las partes en las que se observa este tipo de filiación» SEGALEN, 2001: 58 ss. La insatisfacción implícita de la aplicación de estas categorías — entre ellas especialmente la de «linaje»— lleva a plantear a Segalen categorías alternativas como la de «comunidades tácitas».

43 De hecho, el desarrollo y uso del concepto de «linaje» en la Antropología tiene su propia genealogía, nada inocente por cierto, que es analizada críticamente por Adam Kuper con 
lista del parentesco ${ }^{44}, \mathrm{y}$ asumir que éste se expresa de muy diversas formas en todo tiempo histórico, particularmente el linaje. La categorización unívoca de éste como agnático, por muy cómoda que sea, se ajusta mal a las evidencias documentales de nuestro Medievo, comenzando por el primer texto genealógico conocido para Castilla, el de Fernán Pérez de Ayala.

El argumento del agnatismo en el texto ayalino es superado por la vigencia de los derechos sucesorios que transmiten mujeres y segundones ${ }^{45}$. Sin dejar este ejemplo, destaca un hecho tan poco agnático como el que protagoniza el padre del futuro Canciller cuatro años después de escribir su Libro. Es entonces cuando el cabeza de linaje formaliza dos mayorazgos, uno para Pero López y otro para la hermana de éste, Mencía de Ayala ${ }^{46}$. La creación del segundo vínculo se revela como una maniobra para anular los derechos sucesorios de los Guevara sobre los de Ayala transfiriéndolos al patrimonio de Ceballos. Aunque se trata de una estrategia impecablemente diseñada, podría haberse escogido otra que no implicara la aparente contradicción en relación al no menos aparente agnatismo. Nada de lo anterior impide que Fernán Pérez - en la línea de la Segunda Partida - aluda explícitamente en el Libro del linaje a la sucesión legítima de varón en varón:

Y aquí se acabó el linage de Salcedo e Ayala que veníen de padre e padre siempre al maior ${ }^{47}$.

La literalidad de estos testimonios puede sugerir una contradicción si no se sitúan en perspectiva. Por un lado, reclamando con Rafael Sánchez Saus «el carácter multiforme y proteico del linaje como estructura familiar, su amplia gama de funciones y la complejidad de éstas» ${ }^{48}$. Por otro, poniendo en cuestión el uso y alcance conceptual del «linaje» a partir de las fuentes. En esta tarea debe rechazarse, en mi modesto entender, lo que podríamos llamar «ilu-

su habitual ironía (2005: 163-178). Este trabajo parte de su ya clásico artículo -KUPER, 11 (1982) - y de las demoledoras conclusiones de David Schneider quien llegó a afirmar, en esta línea de deconstrucción crítica disciplinar, que el parentesco «is a non-subject. It exists in the minds of anthropologists but not in the cultures they study». SCHNEIDER, 1972: 51. Recientemente, Alain Boureau ha debatido sobre la «muerte de la antropología» precisamente en relación al papel del medievalismo: BOUREAU, 6 (2010).

44 «El modelo de linaje que Duby observa en la nobleza francesa fue convertido así en una construcción típica-ideal a partir de la cual se evaluaron las estructuras de parentesco de la aristocracia del norte hispánico». PÉREZ, 42 (2010): 170.

45 DACOSTA, 11 (2011); DACOSTA, 2007: 100-102.

46 Mencía era esposa de Beltrán Vélez de Guevara, señor de Oñate, quien poseía legítimos derechos sucesorios sobre el señorío de Ayala que no se ocultan, aunque se reinterpretan, en el Libro del linaje. Sobre esta cuestión DACOSTA, 4 (2010): 293-294.

47 DACOSTA, 2007: 143.

48 SÁNCHEZ SAUS, 17 (1994): 9. 
sión agnática», parafraseando a Pierre Bourdieu ${ }^{49}$. Aparte de la confusión y falta de consenso en la conceptualización del linaje ${ }^{50}$, se detecta en su interpretación una tendencia teleológica, ceñida generalmente a la monocausalidad, y, peor si cabe, la sensación de que en el fondo, estamos ante una realidad precondicionada. Además, en lo que afecta a la cuestión de fondo —el significado social del «linaje»- Goody advertía que la base de los sistemas de parentesco medievales no está en las normas sino en las estrategias adaptativas de cada grupo social ${ }^{51}$. En esta línea se manifiestan algunos trabajos recientes, planteando que el linaje, en suma, «constitue fondamentalement un cadre $\mathrm{d}$ 'appropiation du pouvoir (seigneurial le plus souvent, mais aussi municipal dans les villes) $\rangle^{52}$. A lo mismo apunta Georges Martin cuando pone de manifiesto la importancia del concepto en el reforzamiento de la legitimidad de los monarcas leoneses y castellanos ${ }^{53}$. Dicho en otras palabras, puede ser útil replantear el linaje como una «estrategia de reproducción social» ${ }^{54} \mathrm{y}$, en consecuencia, la literatura genealógica como un «mecanismo de legitimación» $»^{55}$. A falta de resolver la cuestión terminológica y conceptual, ante las evidencias expresadas, la idea del retraso en la implantación del linaje nobiliario en Castilla debería ponerse en entredicho o, al menos, no vincularla causalmente al retraso de los usos genealógicos —entiéndase literarios - entre la nobleza.

\section{NOBLEZA, ORALIDAD Y ESCRITURA}

El uso de recursos genealógicos escritos entre la nobleza castellana parece tardío, al menos desde el expresivo silencio documental. No obstante, dicho retraso quizá no sea tal si se insertan dichos recursos entre los «objetos de memoria» de la nobleza ${ }^{56}$. Estos venían manifestándose en León y Castilla desde el siglo XII en la fundación de monasterios ${ }^{57}$, la onomásti-

49 BOURDIEU, 62-63 (1986).

50 «Muchos problemas relativos al análisis de la familia y el parentesco podrían resolverse mediante distinciones, definiciones y vocabularios más precisos» (GOODY, 1986: 31, nota 2).

51 GOODY, 1986: 315 ss, citado por PÉREZ, 42 (2010): 174.

52 MORSEL, 2007: 149.

53 MARTIN, 2011.

54 PÉREZ, 42 (2010): 174.

55 BECEIRO, 2013: 188.

56 La expresión la tomamos de HEUSCH, 11 (2011): 2. MARTIN (1992: 44), por su parte, los denomina «instrumentos de la memoria».

57 Véase, por ejemplo, el trabajo de Inés CALDERÓN MEDINA, 18 (2008), en el que estos monasterios son considerados expresamente «centros de construcción de la memoria familiar» (364 ss). La relación entre genealogía nobiliaria y promoción de los «respectivos centros monásticos» también es destacada por BECEIRO, 2013: 81. 
$\mathrm{ca}^{58}$, la herencia ${ }^{59}$, el enterramiento familiar ${ }^{60}$ o la heráldica ${ }^{61}$. Comparando esta situación con los referentes franceses o flamencos alto y plenomedievales se ve que el entorno habitual de producción genealógica eran los monasterios condales, fenómeno comparativamente residual en León y Castilla. Ciertamente los efectos de este patrocinio en los siglos XII y XIII no son los mismos, aunque algunos autores señalen precedentes castellanos que no deberían desdeñarse ${ }^{62}$, junto con otros aún más antiguos si ampliamos la muestra a testimonios de esta naturaleza producidos para las casas principescas y condales del ámbito pirenaico y catalán ${ }^{63}$.

El retraso, por tanto, parece referirse a la práctica de la escritura genealógica por parte de la nobleza, retraso que, hasta la irrupción de don Juan Manuel, parece darse en todos los géneros literarios ${ }^{64}$. El argumento no es mío, lo hallamos en la obra de Fernán Pérez de Guzmán:

La verdat e çertidumbre del origin e nasçimiento de los linajes de Castilla, non se puede bien saber sino quanto quedó en la memoria de los antiguos. Ca en Castilla ovo siempre e ay poca diligençia de las antigüedades, lo qual es gran daño ${ }^{65}$.

De esta acusación de nobleza iletrada se librarán su tío el Canciller Ayala y también el padre de éste, Fernán Pérez, cuya obra genealógica conocía. A

58 Para la cronología aludida remito a MARTÍNEZ SOPENA, 4, (1994): 189-197; y desde la perspectiva aquí abordada véanse los recientes trabajos de CALDERÓN MEDINA, 35 (2011): 67-88, y PARDO DE GUEVARA, 39/1 (2009): 27-45.

59 MARTINEZ SOPENA, 2002.

60 Para uno de los linajes más importantes del periodo, los Haro, y sus enterramientos en los monasterios de Cañas y Nájera, véase RUIZ MALDONADO, 1996.

61 PARDO DE GUEVARA, 11 (2011).

62 Es el caso, por ejemplo, del ciclo legendario de Fernán González y los Jueces de Castilla magistralmente estudiado por MARTIN, 1992; y también deben atenderse los precedentes que señala —particularmente la Historia Roderici-MENÉNDEZ PIDAL, 2008: 43.

63 Las denominadas Genealogías de Roda, editadas en su día por Lacarra, son consideradas por SALAZAR Y ACHA (2008: 21) como uno de los textos europeos más antiguos en su género. Sobre la transmisión y reescritura de las Genealogías de Roda, en relación a lo que aquí se aborda, véase BAUTISTA, 7 (2009). A lo anterior debería sumarse la obra de Miró Bonfill, conde de Besalú y obispo de Gerona, que, en palabras de SALRACH, en cierto punto «se convierte en crónica de la memoria genealógica del linaje», 35-1 (2005): 284. Para la obra de Miró Bonfill, remitimos a ZIMMERMANN, 2003.

${ }^{64}$ De facto, sólo en la literatura sapiencial del siglo XIII encontramos material expresamente dirigido a la nobleza, comenzando con el Libro de los doze sabios o Tractado de la nobleza y lealtad, y es bien sabido que su entorno de producción fue la corte castellana. Existen discrepancias sobre si fue ordenado por Fernando III o su hijo Alfonso X, pero no cabe dudar, como señala François Foronda, de la «ambición monárquica» del texto. FORONDA, 7 (2005-2006): 13-36.

65 Generaciones y semblanzas, 18; citado por VAQUERO, 7 (2003). 
pesar de ello no duda en arrojar una sospecha de verosimilitud en lo que toca a la leyenda de origen de su propio linaje:

Algunos del linaje de Ayala dizen que vienen de un infante de Aragón a quien el rey de Castilla dio el señorío de Ayala. E yo ansí lo fallé escrito por don Ferrant Pérez de Ayala, padre deste don Pero López de Ayala, pero non lo leí en estorias nin he dello otra certidumbre ${ }^{66}$.

El señor de Batres es, en este punto, un caso extraordinario en el seno de la nobleza de su tiempo, como lo fueron sus directos parientes Fernán Pérez de Ayala y el Canciller, estando dotados como están, todos ellos, de una potente voz narrativa ${ }^{67}$.

Esto me permite entrar en el tercero de los argumentos que sintetizaba al principio. Creo correcta la hipótesis de Luis Fernández Gallardo cuando destaca «una más prolongada perduración de la oralidad, que pone de manifiesto un retraso más acusado en el acceso a las formas de cultura escrita por parte de la nobleza castellana» al tiempo que señala cómo solo llegado el siglo XV «la figura de Don Juan Manuel dejó así de ser la excepción en un estamento reluctante a la palabra escrita ${ }^{68}$.

Sin embargo, un nuevo problema se plantea al asumir lo anterior: ¿es el genealógico un género nuevo en Castilla? Miguel Calleja trata de responder a ello cuando afirma que «sin una sólida tradición oral de leyendas de orígenes aristocráticos que podemos remontar a los siglos XII y XIII, si no antes», no hubiera sido posible el desarrollo de la literatura genealógica nobiliaria en Castilla a partir del siglo XIV ${ }^{69}$. Ahora bien, según destacó José Mattoso para el caso portugués, estas «tradiciones familiares» son uno más de los aportes de los Livros de linhagens — particularmente en sus narrativas_-, aporte no superior al de la creación trovadoresca ${ }^{70}$, la épica y los primeros romances

66 Generaciones y semblanzas, 15. La cuestión se analiza in extenso en DACOSTA, 2007: 60-61.

67 Para los problemas de interpretación de aspectos como la relación entre narración y audiencia, autor y representación individual, e interacción entre texto y valores sociales, y en suma de lo que concierne a la «voz narrativa», véase MARNETTE y SWIFT, 22 (2011).

68 FERNÁNDEZ GALLARDO, 2006: 452.

69 FERNÁNDEZ GALLARDO, 2006: 136. No obstante, este mismo autor parece vincular la consolidación del linaje nobiliar con la escritura genealógica: «en esta primera etapa en la que las estructuras de parentesco no han generado todavía un esquema de tipo linajístico, la conciencia de los antepasados parece mantenerse en el canal de la oralidad, y de hecho perdurará en esa vía hasta que en los siglos XIV y XV algunos cronistas comiencen a fijarlas por escrito» (FERNÁNDEZ GALLARDO, 2006: 129).

70 Lo trata in extenso MIRANDA, 11 (2011): 13 ss. y nota 11. 
(principalmente el arquetipo cidiano, medular en la genealogía portuguesa), o la incipiente historiografía liberada de sus antecedentes clericales ${ }^{71}$.

Se puede dar la vuelta a los argumentos anteriores para valorar en positivo, de nuevo con Mattoso, la oralidad en un «determinado contexto cultural» ${ }^{72}$. Alain Guerreau, comentando precisamente la aportación de Jack Goody a la cuestión, ha llegado a afirmar — quizá con excesiva rotundidad- que «la Europa medieval ha utilizado siempre y en todas partes la escritura, pero siempre de manera parcial, categorizada y reglamentada» ${ }^{73}$. Admitiendo mal la extensión de su conclusión a tan amplio espacio y tiempo, no es bueno despreciar el papel de la oralidad ${ }^{74}$, ni olvidar que la relación entre ésta y la escritura no es necesariamente contradictoria en la Edad Media, sino más bien «intrínseca al texto medieval» ${ }^{75}$. Cabe recordar una de las recurrentes fórmulas de nuestra diplomática, «sepan quantos este privilegio vieren e oyeren» ${ }^{76}$, en la que se condensa la dialéctica e inseparable relación entre oralidad y escritura.

De facto, el sistema de valores y creencias se transmitía habitualmente de forma oral - y a través de otros medios de comunicación simbólica ${ }^{77}$ — aunque estuviera fundamentado en los contenidos de un libro incontestable, la Biblia, custodiados y traducidos en términos de comprensión por la élite clerical. Por otro lado, tal y como destaca Fernando Gómez Redondo, en determinados géneros literarios medievales, particularmente los que están sometidos a algún tipo de interpretación o representación - del exempla al sermón, del poema épico a la creación juglaresca - la relación entre oralidad y escritura es totalmente directa y necesaria ${ }^{78}$.

En lo que nos ocupa ahora, la nobleza castellana, debe valorarse la adquisición de prácticas escriturales propias, distintas de aquellas en las que habían participado sus ancestros directa o indirectamente: la donación monástica, el diploma regio, el fuero villano o la evidencia epigráfica. Creo que dicha adquisición tuvo importantes efectos en la manera de ver el mundo de la nobleza y, sobre todo, en la forma en la que quería ser percibida por el conjunto de

71 Traduzco casi literalmente las palabras del profesor MATTOSO, 1983: 9.

72 MATTOSO, 1983: 9.

73 GUERREAU, 2002: 167.

${ }^{74} \mathrm{Y}$ menos para el asunto que nos ocupa. Recientemente BUTAUD y PIETRI (2006: 18 ss) han destacado la importancia de la oralidad en la transmisión de las genealogías medievales.

75 PAREDES NÚÑEZ, 1998: 125.

76 Este, concretamente, está extraído de un privilegio rodado de Alfonso X regulando las exenciones de los caballeros del concejo de Béjar, dado el 18 de junio de 1261 en Sevilla (BARRIOS y MARTÍN EXPÓSITO, 1986, doc. 5).

77 Sobre esto, veáse: SCHMITT, 51 (1996): 3-36, y, también, KUCHENBUCH, 2003: 146 ss.

78 GÓMEZ REDONDO, 1998: 258 ss. 
la sociedad. Cosa bien distinta es afirmar que la nobleza que escribe en la Castilla del Trescientos es, en esencia, distinta de la que no lo hace. No puede obviarse el hecho de que la cultura medieval «es fundamentalmente 'memorial' $\gg{ }^{79}$ y simbólica incluso «en un mundo de progresivo uso del escrito, como es el de los siglos finales de la Edad Media» ${ }^{80}$. De hecho, últimamente se está destacando que incluso la «escritura de gestión» - como algunos autores denominan - potencia una memoria que, por lo corriente en la Edad Media, tiene un carácter estamental cuando no directamente institucional ${ }^{81}$. En resumen, la escritura se erige como un mecanismo más de reproducción y representación del poder de quien practica la primera y aspira a lo segundo, y esto me lleva de nuevo a nuestro excepcional protagonista, Fernán Pérez de Ayala.

Porque a diferencia de las genealogías nobiliarias de finales del siglo XV, la de Fernán Pérez está redactada por el fundador de una nueva dinastía señorial y no por un descendiente que pretende recabar y potenciar la memoria del linaje ${ }^{82}$. Se trata, además, de un noble letrado, rara avis en la Castilla de su tiempo, en quien se intuye la poderosa influencia de su tío el Cardenal Barroso y, quizá también, la del conde Pedro de Barcelos ${ }^{83}$. Además, si como sospechan especialistas más acreditados, «el siglo XIV se diría una época especialmente afectada por la pérdida de textos» y encontramos otros aislados y fuera de contexto ${ }^{84}$, como ocurre con el Libro del linaje de los señores de Ayala, la cuestión dista de quedar clarificada.

79 OLÁBARRI, 1996: 149.

80 BECEIRO, 12 (1994).

81 En esta perspectiva se sitúan trabajos como los de JORNET, 2006, BARRET, 2007, o CALLEJA PUERTA, 2013. En la misma línea, véanse las aportaciones al volumen colectivo dirigido por CONTAMINE y VISSIÈRE, 2010. No siempre de forma expresa, estas sugerentes hipótesis sobre la «memoria de la institución» - o si se quiere memoria colectiva «institucionalizada» - bebe de la tradición constructivista francesa — de Michel Foucault a Pierre Nora- Sin olvidarla, creo que esta perspectiva de análisis podría verse enriquecida por las valientes sugerencias teóricas de la antropóloga DOUGLAS, 1996.

82 Asunto que queda expresamente definido en el título - $\mathrm{y}$ en la causa formal - de su texto genealógico por mucho que el texto se remonte al legendario don Vela: «Este es el libro del linaje de los Señores de Ayala. Desde el primero que se llamó don Vela hasta mí, don Fernán Pérez, que le fiz a honra e gloria de Dios, e pro de mío linage, e para que sean buenos e homildes e sirvan a Dios e al rey los que de mí vinieren» DACOSTA, 2007: 135. Para el valor histórico de los paratextos ibéricos medievales en el sentido aquí expuesto remito al reciente dossier monográfico coordinado por Carlos Heusch titulado «Paratextes et stratégies de pouvoir dans la péninsule Ibérique au Moyen», HEUSCH, 2012.

${ }^{83}$ He sostenido esta posibilidad en DACOSTA, 11 (2011): 7, hipótesis que se confirma en la idea - a verificar - de que el Livro de Pedro de Barcelos fue «o libro mais útil, e mais consultado da Península exceptuada a Biblia» (LAPA, 1982: 306, citado por PAREDES NÚÑEZ, 1998: 125).

${ }^{84}$ El entrecomillado está tomado de BAUTISTA, 2008: 206. 
Si bien la cuestión planteada críticamente en este trabajo, esto es, el retraso en la aparición de la literatura genealógica castellana no parece resuelto, al menos pueden rechazarse algunas hipótesis y, sobre todo, evitar que la cuestión quede reducida a un único factor: ¿anomalía o excepción? Creo factible rechazar la primera posibilidad, y poderosos indicios apuntan en contra de la segunda, por mucho que el primer texto genealógico castellano se antoje excepcional, tanto como lo fueron su autor o su hijo y continuador el Canciller Ayala ${ }^{85}$.

\section{Algunas PROpUestas de anÁlisis}

La primera cuestión expuesta, la del retraso de la literatura genealógica de la nobleza, se ha abordado en términos de «anomalía». Si la perspectiva adoptada por Deyermond y otros estudiosos respecto de la literatura perdida en Castilla es la correcta, quizá lo expuesto obedezca a un problema de transmisión truncada de este tipo de escritos. Algunos indicios hay de ello, y debe contarse también con el hecho de que la riqueza de nuestros archivos y bibliotecas aún no está del todo explorada. Sin embargo, las evidencias más firmes apuntan hacia un retraso castellano en este sentido, retraso que, en cualquier caso, debe ser explicado en términos de multicausalidad. Se ha avanzado mucho en aspectos como el de la transmisión de modelos literarios, fenómeno particularmente importante en la Península Ibérica en la baja Edad Media, reflejo de una intensa movilidad geográfica de efectivos nobiliarios - permanente o temporal- de distinto origen regional ${ }^{86}$. La difusión y retroalimentación de los modelos culturales de la nobleza europea también es un hecho cada vez mejor conocido. Dicho de otra forma, la aquí anunciada excepcionalidad de algunos textos genealógicos castellanos, su aparente marginalidad, debe ser puesta en relación con un contexto más amplio y dinámico.

Por otro lado, se ha expuesto que este problema está vinculado de forma nuclear a la cuestión del «linaje», toda vez que la literatura genealógica es reflejo de la autoimagen que cada familia - y en conjunto el estamento nobiliario- quiso transmitir en cada momento. Esta segunda cuestión trasciende la primera en distintos planos teóricos y metodológicos, y por ello debe merecer una mayor atención. Sin ánimo de trazar un programa de investigación, quisiera exponer algunas propuestas. La primera, el examen de métodos y conceptos de otras disciplinas - en particular la antropología — para el análisis de la sociedad medieval. Es encomiable el esfuerzo de algunos medievalistas por revisar el alcance de la denominada «antropología histórica», pero el debate se

\footnotetext{
85 Abordo esta perspectiva en DACOSTA, 2013.

86 Para esto remito a la reciente y completa síntesis de MARTÍNEZ SOPENA, 2010.
} 
enriquecerá si se lleva a terrenos más concretos como el de la caracterización, origen y evolución de eso que comúnmente llamamos linaje nobiliario.

En este último sentido, algunos aspectos comienzan a abordarse desde Portugal, Francia y, también, España. La denunciada «ilusión agnática» requiere de un análisis lexicológico sistemático del término «linaje» en los documentos castellanos desde principios del siglo XIII y su relación conceptual con los términos usuales en la época inmediatamente precedente. Este trabajo, avanzado hoy por José Carlos Ribeiro Miranda - y con propuestas de método tan concretas como las de Ana Isabel Carrasco-, puede completarse con análisis de caso y de contexto. Estos últimos son relativamente sencillos de realizar gracias a las numerosas aportaciones de nuestra historiografía sobre la nobleza, particularmente la plenomedieval. Sin embargo, se precisa continuar la tarea para periodos más tardíos donde los testimonios genealógicos articulan discursos nobiliarios más explícitos. En ellos el concepto de linaje tiene un papel central que cabe interpretar en términos de reproducción social. Sin embargo, en este escenario participan más actores que la nobleza. El papel de Alfonso X en la difusión de conceptos como nobleza, linaje e, incluso, agnatismo, es decisivo, y se está revelando que la codificación de aquellos operó como una herramienta de control político ${ }^{87}$. Este contexto, el del juego de equilibrios entre monarquía y nobleza, puede explicar la apropiación del concepto por parte de amplios sectores de este estamento. Y es aquí donde surge un nuevo reto, el de dilucidar en el terreno de lo social qué manifestaciones concretas adoptó eso que llamamos linaje nobiliario, y cómo fue evolucionando en los siglos finales de nuestro Medievo.

\section{BIBLIOGRAFÍA}

Alonso Pedraz, Martín, Diccionario Medieval Español, Salamanca, Universidad Pontificia, 1986, 2 vols.

Álvarez Borje, Ignacio, «Los señoríos de los Rojas en 1352», en Carlos Estepa y Cristina Jular (coords.), Los señorios de behetría, Madrid, CSIC, 2002.

Álvarez Borje, Ignacio, «Vasallos, oficiales, clientes y parientes. Sobre la jerarquía y las relaciones internobiliarias en la Castilla medieval (c. 1100-c. 1350)», Hispania, LXX/235 (2010), 359-390.

Aurell, Jaume, «From Genealogies to Chronicles: the power of the form in medieval catalán historiography», Viator, 36 (2005), 235-264.

Aurell, Jaume, «Memoria dinástica y mitos fundadores: la construcción social del pasado en la Edad Media», en Arsenio Dacosta, José Ramón Díaz de Durana y Ramón Prieto Lasa (eds.), La conciencia de los antepasados. La construucción de

87 MARTIN, 2004 y 2011.

Hispania, 2015, vol. LXXV, nº. 251, sept.-diciembre, págs. 617-640, ISSN: 0018-2141, e-ISSN: 1988-8368, doi: 10.3989/hispania.2015.018 
la memoria de la nobleza en la Baja Edad Media, Madrid, Marcial Pons, 2014; 313-330.

Barret, Sébastien, «L'institutionnalisation de la mémoire: les archives ecclésiastiques», en Giancarlo Andenna (dir.), Pensiero e sperimentazione istituzionali nella Societas Christiana (1046-1250), Atti della sedicesima Settimana internazionale di Studio, Mendola, 26-31 agosto 2004, Milán, Vita et Pensiero, 2007; 463-485.

Barrios, Ángel y Alberto Martín Expósito, Documentación medieval de los Archivos Municipales de Béjar y Candelario, Salamanca, Diputación de Salamanca, 1986.

Bautista, Francisco, "Genealogía y leyenda. El surgimiento de los reinos de Castilla y Aragón», e-Spania. Revue électronique d'études hispaniques médiévales, 7 (2009) [en línea]. Disponible en: http://e-spania.revues.org/18086 [consultado el 25 de julio de 2011]

Bautista, Francisco, «Sobre la historia literaria castellana del siglo XIV», en Javier San José (dir.), La fractura historiográfica: las investigaciones de Edad Media y Renacimiento desde el Tercer Milenio, Salamanca, SEMyR, 2008; 205-214.

Beceiro Pita, Isabel, «El escrito, la palabra y el gesto en las tomas de posesión señoriales», Stvdia Historica. Historia Medieval, 12 (1994), 53-82.

Beceiro Pita, Isabel. «El uso de los ancestros por la aristocracia castellana: el caso de los Ayala», Revista de Dialectología y Tradiciones Populares, 50 (1995), 57-58.

Beceiro Pita, Isabel, «La memoria y el discurso de la nobleza en los relatos genealógicos castellanos (1370-1540)», en Arsenio Dacosta, Ramón Prieto Lasa y José Ramón Díaz de Durana (eds.), La conciencia de los antepasados. La construucción de la memoria de la nobleza en la Baja Edad Media, Madrid, Marcial Pons, 2014; 179-197.

Beceiro, Isabel y Ricardo Córdoba de la Llave, Parentesco, poder y mentalidad. La nobleza castellana, siglos XII-XV. Madrid: CSIC, 1990.

Bloch, Marc, La Sociedad Feudal, Madrid, Akal, 1986.

Bourdieu, Pierre, «L'illusion biographique», Actes de la recherche en sciences sociales, 62-63 (1986): 69-72.

Boureau, Alain, «Questions disputées quomodo Historiam scribere», L'Atelier du Centre de recherches historiques, 6 (2010) [en línea]. Disponible en: http://acrh.revues. org/2755. [consultado el 25 de noviembre de 2012]

Butaud, Germain y Valérie Pietri, Les enjeux de la généalogie. XII $-X V I I I^{e}$ siècles, París, Autrement, 2006.

Calderón Medina, Inés, «El impulso nobiliario a la expansión del Císter en el Reino de León. La parentela de Ponce de Cabrera en los monasterios de Santa María de Moreruela y San Esteban de Nogales», Medievalismo, 18 (2008), 341-374.

Calderón Medina, Inés, «La antroponimia de la nobleza leonesa plenomedieval. Un elemento de construcción de identidad y memoria nobiliaria», Miscelánea Medieval Murciana, 35 (2011), 67-88.

Calderón Medina, Inés, Cum magnatibus regni mei. La nobleza y la monarquía leonesas durante los reinados de Fernando II y Alfonso IX (1157-1230), Madrid, CSIC, 2011. 
Calleja Puerta, Miguel, El conde Suero Vermúdez, su parentela y su entorno social. La aristocracia asturleonesa en los siglos XI y XII, Oviedo, Universidad, 2001.

Calleja Puerta, Miguel, «El factor genealógico: posibilidades y límites de la documentación de archivo para la elaboración de historias familiares», Emblemata, 16 (2010), 123-153.

Calleja Puerta, Miguel, «Cartulario y construcción de la memoria monástica en los reinos de León y Castilla durante el siglo XII», en Véronique Lamazou-Duplan y Eloísa Ramírez Vaquero (dirs.), Les cartulaires médiévaux. Écrire et conserver la mémoire du pouvoir, le pouvoir de la mémoire, Pau, Universtié de Pau et des Pays de 1'Adour, 2013; 187-208.

Carrasco Manchado, Ana Isabel, «Nuevas herramientas para la historia de la Edad Media hispánica: los corpus textuales informatizados», En la España medieval, 34 (2011), 343-372.

Cátedra, Pedro, La Historia de la Casa de Zúñiga, otrora atribuida a mosén Diego de Valera, Salamanca, SEMyR, 2003.

Cirot, Georges, «Anecdotes et légendes du temps d'Alphonse VIII», Bulletin Hispanique, 28 (1926): 246-259, y 29 (1927): 145-173, 241-254 y 337-350.

Contamine, Philippe y Laurent Vissière (dirs.), Défendre ses droits, construire sa mémoire. Les chartriers seigneuriaux, XIII $-X X I^{e}$ siècle, París, Société de l'histoire de France, 2010.

Contreras, Jaime, «Linaje y cambio social: la manipulación de la memoria», Historia Social, 21 (1995), 105-124.

Dacosta, Arsenio, El «Libro del linaje de los señores de Ayala» y otros textos genealógicos. Materiales para el estudio de la conciencia del linaje en la Baja Edad Media, Bilbao; Universidad del País Vasco, 2007.

Dacosta, Arsenio, «De la conciencia del linaje a la defensa estamental. Acerca de algunas narrativas nobiliarias vascas», Medievalista [en línea], 8 (2010). Disponible en: http://www2.fcsh.unl.pt/iem/medievalista/MEDIEVALISTA8/dacosta8007.html [consultado el 2 de febrero de 2013]

Dacosta, Arsenio, «Image and Biography of Chancellor Ayala: Report of an Impossibility», Imago temporis: Medium Aevum, 4 (2010): 287-305.

Dacosta, Arsenio, «Memoria linajística, legitimación dinástica y justificación personal en el Libro de linaje de los señores de Ayala y sus continuaciones», e-Spania. Revue électronique d'études hispaniques médiévales, 11 (2011) [en línea]. Disponible en http://e-spania.revues.org/20260 [consultado el 24 de noviembre de 2012]

Dacosta, Arsenio, «Mecanismos y articulaciones discursivas en la construcción de la memoria genealógica: el caso de los Ayala», en Arsenio Dacosta, Ramón Prieto Lasa y José Ramón Díaz de Durana, (eds.) La conciencia de los antepasados. La construcción, de la memoria de la nobleza en la Baja Edad Media, Madrid, Marcial Pons Historia, 2014; 119-142.

Douglas, Mary, Cómo piensan las instituciones, Madrid, Alianza, 1996.

Duby, Georges, «Remarques sur la littérature géneálogique en France aux XI ${ }^{\mathrm{e}}$ et XII ${ }^{\mathrm{e}}$ siècles», Hommes et structures au Moyen Âge, París, Flammarion, 1973; 287-298. 
Dutton, Brian (ed.), La «Vida de San Millán de la Cogolla», Londres, Tamesis Books, 1967.

Escalona, Julio, «Épica, crónicas y genealogías. En torno a la historicidad de la leyenda de los Infantes de Lara», Cahiers de Linguistique Hispanique Médiévale, 23 (2000), 113-176.

Fernández Gallardo, Luis, «La biografía como memoria estamental», en José Manuel Nieto Soria (coord.), La monarquía como conflicto en la Corona castellanoleonesa (c. 1230-1504), Madrid, Sílex, 2006; 423-488.

Foronda, François, «Sociedad política, propaganda monárquica y régimen en la Castilla del siglo XIII. En torno al Libro de los Doze Sabios», Edad Media. Revista de Historia, 7 (2005-2006): 13-36.

Gómez Redondo, Fernando, «Narradores y oyentes en la literatura ejemplar», en Juan S. Paredes Núñez (ed.), Tipología de las formas narrativas breves románicas medievales, Granada, Universidad, 1998; 253-310.

Goody, Jack, La evolución de la familia y del matrimonio en Europa, Barcelona, Herder, 1986.

Guerreau, Alain, El futuro de un pasado. La Edad Media en el siglo XXI, Barcelona, Crítica, 2002.

Guerreau-Jalabert, Anita, «El sistema de parentesco medieval: sus formas (real/espiritual) y su dependencia con respecto a la organización del espacio», en Reyna Pastor (ed.), Relaciones de poder, de producción y parentesco en la Edad. Media y Moderna. Aproximación a su estudio, Madrid, CSIC, 1990; 85-106.

Heusch, Carlos, «La pluma al servicio del linaje», e-Spania. Revue électronique d'études hispaniques médiévales [en línea]. 11 (2011). Disponible en: http://espania.revues.org/20313 [consultado el 14 de marzo de 2013] Disponible en: http:// www.gcoe.lit.nagoya-u.ac.jp/eng/result/pdf/157-170_REIMITZ.pdf [consultado el 12 de febrero de 2013]

Heusch, Carlos (ed). «Paratextes et stratégies de pouvoir dans la péninsule Ibérique au Moyen Âge», Cahiers d'études Hispaniques Médiévales, 35, 2012.

Jornet, Núria, «La relación con los recuerdos: la autoridad y el poder de la memoria», en $\mathrm{M}^{\mathrm{a}}$ Milagros Rivera (coord.), Las relaciones en la historia de la Europa medieval, Valencia, Tirant lo Blanc, 2006; 18-60.

Krus, Luís, A Concepção Nobiliárquica no Espaço Ibérico: Geografia dos Livros de Linhagens Medievais Portugueses, 1280-1380. [Tesis doctoral], Lisboa, Universidade Nova de Lisboa, 1989.

Krus, Luís, «As origens lendárias dos Condes de Trastâmara», Penélope. Fazer e desfazer a História. 8 (1992), 43-49.

Kuchenbuch, Ludolf, «Ecriture et oralité. Quelques complements et approfondissements», en Jean Claude Schmitt y Otto Gerhard Oexl (dirs.), Les tendences actuelles de l'Histoire du Moyen Âge en France et Allemagne, París, Publications de la Sorbonne, 2003; 143-166.

Kuper, Adam, «Lineage Theory: A Critical Retrospect», Annual Review of Anthropology, 11 (1982), 71-95. 
Kuper, Adam, «Descent theory», en The Reinvention of Primitive Society: Transformations of A Myth, Londres, Routledge, 2005; 163-178.

La Roncière, Charles de, «De la mémoire vécue à la tradition, perception et enregistrement du passé», en Actes des congrès de la Société des historiens médiévistes de l'enseignement supérieur public. $13^{e}$ Congrès. Temps, mémoire, tradition au Moyen-Âge. Aix-en-Provence, Université de Provence, 1982; 267-379.

Ladero Quesada, Miguel Ángel, «No curemos de linaje ni hazañas viejas... Diego Hernández de Mendoza y su visión hidalga de Castilla en tiempo de los Reyes Católicos», Boletín de la Real Academia de la Historia, 198 (2001): 205-314

Lapa, Manuel Rodrigues, Liçoes de literatura portuguesa. Época medieval, Coimbra, Coimbra Editora, 1982.

Larrea, Juan José, «La infanzonía en una perspectiva comparada: infanzones y ariman$n i$ del ordenamiento público al feudal», en Pierre Bonnassie (ed.), Fiefs et féodalité dans l'Europe méridionale (Italie, France du Midi, Péninsule Ibérique) du $X^{e}$ au XIII ${ }^{e}$ siècle, Toulouse, CNRS/Université de Toulouse-Le Mirail, 2002; 363-396.

Líbano, $\mathrm{M}^{\mathrm{a}}$ Ángeles y Villacorta, Consuelo, «Aproximación léxica a las estructuras y grupos sociales en el espacio geográfico vascongado (siglos XV y XVI)», Revista de Investigación Lingüística, 11 (2008), 165-188.

Marnette, Sophie y Helen Swift, «Que veut dire voix narrative?», Cahiers de Recherches Médiévales et Humanistes, 22 (2011): 1-7 [en línea]. Disponible en: http://crm.revues.org/12505 [consultado el 15 de abril de 2013]

Martin, Georges, Les Juges de Castille. Mentalités et discours historique dans l'Espagne médiévale, París, Klincksieck, 1992.

Martin, Georges, «Control regio de la violencia nobiliaria. La caballería según Alfonso X de Castilla (comentario al título XXI de la Segunda Partida)», en Isabel Alfonso, Julio Escalona y Georges Martin (coords.), Lucha politica: condena y legitimación en la España medieval, Lyon, ENS Éditions, 2004; 219-234.

Martin, Georges, «Linaje y legitimidad en la historiografía regia hispana de los siglos IX al XIII», e-Spania. Revue électronique d'études hispaniques médiévales [en línea]. 11 (2011). Disponible en: http://e-spania.revues.org/20335 [consultado el 14 de marzo de 2013]

Martin, Georges, «La leyenda de los Siete infantes de Salas y su enseñanza sobre solidaridad linajística», e-Spania. Revue électronique d'études hispaniques médiévales [en línea]. 14 (2012), Disponible en: http://e-spania.revues.org/22032 [consultado el 14 de marzo de 2013]

Martínez García, Luis, «Los pactos de benefactoria de la red feudal leonesa y castellana (siglos X-XII)», Hispania, LXX/235 (2010), 325-358.

Martínez Sopena, Pascual, «Parentesco y poder en León durante el siglo XI. La casata de Alfonso Díaz», Stvdia Historica. Historia Medieval, 5 (1987), 33-87.

Martínez Sopena, Pascual, «Notas sobre la antroponimia hispánica medieval», $\mathrm{Me}$ dievalismo, 4 (1994), 189-197.

Martínez Sopena, Pascual, «La evolución de la antroponimia de la nobleza castellana entre los siglos XII y XIV», en Carlos M. Reglero de la Fuente (coord.), Poder y 
sociedad en la Baja Edad Media Hispánica. Estudios en homenaje al Profesor Luis Vicente Díaz Martín, Valladolid, Universidad de Valladolid, 2002, 1; 461479.

Martínez Sopena, Pascual, «La aristocracia hispánica. Castilla y León (siglos XXIII)», Bulletin du centre d'études médiévales d'Auxerre [en línea]. Hors série $\mathrm{n}^{\circ}$ 2 (2008). Disponible en: http://cem.revues.org/10052 [consultado el 1 de octubre de 2012]

Martínez Sopena, Pascual, «La movilidad de la nobleza (España, ca. 1250-1350)», en Sandro Carocci (ed.), La mobilità sociale nel Medioevo, Roma, École Française de Rome, 2010; 209-238.

Mattoso, José, Narrativas dos Livros de Linhagens, selecção, introdução e comentarios, Lisboa, Casa da Moeda, 1983.

Mattoso, José, «La littérature généalogique et la culture de la noblesse au Portugal (XIII ${ }^{\mathrm{e}}-\mathrm{XIV}^{\mathrm{e}}$ siècles)», Bulletin des Études Portugaises et Brésiliennes. 44-45 (1983-1985), 73-92.

Mattoso, José, «O léxico feudal», en Naquele Tempo. Ensaios de História Medieval, Lisboa: Temas e Debates / Círculo de Leitores, 2009a; 109-125.

Mattoso, José, «A nobreza medieval portuguesa no contexto peninsular», en Naquele Tempo. Ensaios de História Medieval, Lisboa: Temas e Debates / Círculo de Leitores, 2009b; 311-330.

Maurel, Christian, «Construction généalogique et développement de l'État moderne. La généalogie des Bailleul», Annales. Économies, Sociétés, Civilisations, 46/4 (1991), 807-825.

Menéndez Pidal, Faustino, La nobleza en España: ideas, estructuras, historia, Madrid, Fundación Cultural de la Nobleza Española, 2008.

Miranda, José Carlos Ribeiro, «O argumento da linhagem na literatura ibérica do séc. XIII», e-Spania. Revue électronique d'études hispaniques médiévales [en línea]. 11 (2011). Disponible en: http://e-spania.revues.org/20347 [consultado el 14 de marzo de 2013]

Moreno Núñez, José Ignacio, «Mayorazgos arcaicos en Castilla», En la España Medieval, 5 (1984), 695-708.

Morsel, Joseph, «Le médiéviste, le lignage et l'effect de réel. La construction du Geschlecht par l'archive en Haute-Allemagne à partir de la fin du Moyen Âge», Revue de Synthèse, 125 (2004), 83-110.

Morsel, Joseph, L'histoire (du Moyen Âge) est un sport de combat, París, LAMOPParis I, 2007.

Nassiet, Michel, «Parenté et succession dynastique aux $14^{\mathrm{e}}$ et $15^{\mathrm{e}}$ siècles», Annales. Histoire, Sciences Sociales, 50 (1995), 621-644.

Nieto Soria, José Manuel, «Conflicto político e invención histórica en algunos libros de blasón castellanos en tiempos de los Reyes Católicos», Cahiers de Linguistique Hispanique Médiévale, 29 (2006), 301-316.

Olábarri, Ignacio, «La resurrección de Mnemósine: historia, memoria, identidad», en Ignacio Olábarri y Francisco J. Caspistegui (eds.), La «nueva» historia cultural: 
la influencia del postestructuralismo y el auge de la interdisciplinariedad, Madrid, Editorial Complutense, 1996; 145-174.

Pallarés, $\mathrm{M}^{\mathrm{a}}$ Carmen y Portela, Ermelindo, «Los mozos nobles. Grandes hombres si fueran hijos solos», Revista d'Història Medieval, 5 (1994), 55-74.

Pardo de Guevara y Valdés, Eduardo, «Identidad y memoria genealógica. Una aportación al estudio de la antroponimia medieval gallega», Anuario De Estudios Medievales, 39/1 (2009), 27-45.

Pardo de Guevara y Valdés, Eduardo, «Las armas de los Limia y sus derivaciones (siglos XIII-XV)», e-Spania. Revue électronique d'études hispaniques médiévales, 11 (2011) [en línea]. Disponible en: http://e-spania.revues.org/20540 [consultado el 24 de noviembre de 2012]

Pardo de Guevara, Eduardo, «La materia genealógica en la literatura histórica medieval. La conformación de un género histórico», en De linajes, parentelas y grupos de poder. Aportaciones a la historia social de la nobleza bajomedieval gallega, Madrid, Fundación Cultural de la Nobleza Española, 2012: 19-31 (publicado originalmente en José María Soto Rábanos (coord.), Pensamiento medieval hispano: homenaje a Horacio Santiago-Otero, Madrid, CSIC, 1998, I; 393-403).

Paredes Núñez, Juan Salvador, «Comparativismo e interdisciplinariedad. En torno a los nobiliarios medievales portugueses», Filología Románica, 8 (1991), 171-178.

Paredes Núñez, Juan Salvador, Las narraciones de los «livros de linhagens», Granada, Universidad de Granada, 1995.

Paredes Núñez, Juan Salvador, «El relato genealógico», en Juan S. Paredes Núñez (ed.), Tipología de las formas narrativas breves románicas medievales, Granada, Universidad, 1998; 123-142.

Pastor, Reyna (dir.), Relaciones de poder, de producción y parentesco en la Edad. Media y Moderna. Aproximación a su estudio, Madrid, CSIC, 1990.

Pastor, Reyna, «Familias y linajes. Subpoblaciones monacales y sus redes. Siglos X al XVIII. Presentación», Hispania, LIII/185 (1993), 791-800.

Pérez, Mariel, «En torno a las estructuras de parentesco de la aristocracia castellanoleonesa. Revisión de los modelos interpretativos dominantes», Anales de Historia Antigua, Medieval y Moderna, 42 (2010), 153-174.

Prieto Lasa, José Ramón, Las leyendas de los señores de Vizcaya y la tradición melusiniana, Madrid, Fundación Ramón Menéndez Pidal, 1995.

Reimitz, Helmut, «The social logic of historiographical compendia in the Carolingian period», en Osamu Kano (ed.), Herméneutique du texte d'histoire, Nagoya University, 2012.

Ruiz Domenec, José Enrique, La memoria de los feudales, Barcelona, Humanitas, 1984.

Ruiz Maldonado, Margarita, Escultura funeraria del siglo XIII: los sepulcros de los López de Haro, Salamanca, Universidad Salamanca, 1996.

Salazar y Acha, Jaime de, Manual de genealogía española, Madrid, CSIC, 2008.

Salrach, Josep María, «Michel Zimmermann, Écrire et lire en Catalogne», Mélanges de la Casa de Velázquez, 35-1 (2005), 281-286. 
Sánchez de Mora, Antonio, Los Lara. Un linaje castellano de la plena Edad Media, Burgos, Diputación Provincial, 2007.

Sánchez Saus, Rafael, «De armerías, apellidos y estructuras de linaje», En la España medieval, 17 (1994), 9-16.

Schmitt, Jean-Claude, «La culture de 1'Imago», Annales. E.S.C., 51 (1996): 3-36.

Schneider, David, «What is Kinship All About?», en Priscilla Reining (ed.), Kinship Studies in the Morgan Centennial Year, Washington D.C., The Anthropological Society of Washington, 1972; 32-63.

Segalen, Martine, Antropología histórica de la familia, Madrid, Taurus, 2001.

Torres Sevilla-Quiñones de León, Margarita C., Linajes nobiliarios en León y Castilla siglos IX-XIII, Valladolid, Junta de Castilla y León, 1999.

Torres Sevilla-Quiñones de León, Margarita C., «Monarquía y nobleza: las transformaciones en el territorio leonés en los siglos X y XI a través del estudio del parentesco», Lletres Asturianes, 102 (2009). 93-115.

Vaquero, Mercedes, «Cultura nobiliaria y biblioteca de Fernán Pérez de Guzmán», Revista Lemir, 7 (2003) [en línea]. Disponible en: http://parnaseo.uv.es/Lemir/ Revista/Revista7/Vaquero/MercedesVaquero.htm [consultado el 20 de junio de 2012]

Vasconcelos e Sousa, Bernardo, «Linhagem e identidade social na nobreza medieval portuguesa (séculos XIII-XIV)», Hispania, LXVII/227 (2007). 881-898.

Vasconcelos e Sousa, Bernardo, D. Afonso IV, Lisboa, Temas\&Debates / Círculo de Leitores, 2009.

Wood, Ian, "Genealogy defined by women. The case of the Pipinids», en Leslie Brubaker y Julia Smith (eds.), Gender in the Early Medieval World. East and West. 300-900, Cambridge, Cambridge Univ. Press, 2004; 234-256.

Zimmermann, Michel, Écrire et lire en Catalogne: $I X^{e}-X I I^{e}$ siècle, Madrid, Casa de Velázquez, 2003, 2 vols.

Recibido: $21 / 06 / 2013$

Aceptado: 16/11/2013 